\section{IJ§ER}

ISSN: 2149-5939
International Journal of Social Sciences and Education Research

Online, http://dergipark.gov.tr/ijsser

Volume: 1(2), 2015

\title{
Kamu hizmetlerinin pazarlanması çalışanların mutluluğu ile ölçülür
}

\author{
Marketing of public service evaluates with happiness of employees
}

\author{
Sefer Gümüş1 Gökhan Öner²
}

\begin{abstract}
Received Date: $01 / 02$ / 2015
Accepted Date: $01 / 04$ / 2015

$\ddot{O} z$

Devlet bir kavramdır. Devleti hükümetler yönetir. Devletin her kademede çalışanları devletin memurlarıdır. Görev ve sorumlulukları yasa ve yönetmeliklerle belirlenmiştir. Çalışanların mutluluğu ve memnuniyeti devlet hizmetlerinin başarılı olarak yürütülmesini sağlar. Bu da devletin başarısı ve geleceği için çok önemlidir. Çalışanların memnun edilmesi, çalışanların devletine bağlılı̆̆ını anlatır. Çalışanların memnuniyeti, genel olarak devletin kurum ve kuruluşlarında kişilere ve makamlara bă̆lllı̆̆ ilgili değil, devletin tüzel kişiliğine sevgiden ve saygıdan geçer. Devlette devamlılık esastır. Kişilere bağlı değil, görevlerine bağlılıkla ölçülmelidir. Bu anlamda çalışanların asıl ve türev görevlerine iliş̧kin memnuniyet düzeylerinin ölçülmesi ve bu tür çalışmaların kamuoyu ile paylaşılması halkın devlete olan güveni sağlamlaştııır. Yapılan birçok araştırmalarda kamu hizmetlerinde daha etkin ve etkili hizmetin çalışan memnuniyeti ya da memnuniyetsizliği ile doğru orantılı olduğu görülmüşür. Özelleştirme kapsamında devlet birçok asıl görevini özel sektöre devretmiştir. Bu anlamda devlet hizmetlerinin de pazarlanmasına gereksinim vardır. Araştırmamızda bu değişkene de yer verilmiştir. Devletin her kurum ve kuruluşu saygındır. Bu araştırma da devletin saygın kurum ve kuruluşlarında çalışanlardan 117 kişi üzerinde yapılmış ve konu ile ilgili görüş ve önerileri alınmıştır. Alan araştırması kamuda çalışan 117 kişi ile anket yöntemi ile yapılmıştır. 117 çalışana uygulanan anket ile toplanan veriler SPSS for Windows v. 17.0 programı ile çözümlenmiştir. Veriler çözümlenmeden önce EDA (Exploratory Data Analysis/Açıklayıcı Veri Analizi) ile toplanan verilerin belirlenen sinırlar içinde olup olmadığ kontrol edilmiş ve gerekli düzeltmeler yapılmuștır. Araştırmada istatistik analiz ve sentez metotları kullanılmış, çalışmanın raporu yazılmış gereken bölüme konuşlandırılmıştır. Araştırmanın sonucunda çalışanların çalışma saatleri ve kurumsal hizmetlerden ve iş sağllğ ve güvenliğinden memnun olmada sorun yaşadıkları, performans değerlendirmesinden, meslek, çalışma mekanı ve güvenlikten, yönetim ve yönetmelikler ve kurumsal bağlllık konularında ise memnun oldukları tespit edilmiştir.
\end{abstract}

Anahtar Sözcükler: Çalışan memnuniyeti, Kamu hizmeti, Hizmet pazarlaması

\begin{abstract}
State is a concept. Government manages the states. Civil servant works all levels of the state. Duties and responsibilities are determined by the laws and regulations. Happiness and satisfaction of the employees ensure successful implementation of government services. It is very important for the future of the state. Employee satisfaction tell us loyalty of the state. Satisfaction of employees in state institutions and the people in general and not about loyalty to the authorities, the state pass through the love and respect of the legal entity. State continuity is essential. Not depends on the person, should be determined devotion to duty. If the satisfaction level measures, public confidence in the state will strengthen. Public services influences happiness and satisfaction of the employees. The States turned over the main task to the private sector. Public service needs to marketing. Our research is also included in this variable. The research is made by a survey that is implemented 117 public workers. At the end of research identified that the workers aren't satisfied about working hours and corporate services and occupational health and safety, the workers are satisfied about performance evaluation, profession, working place and safety, management and regulations and institutional commitment.
\end{abstract}

Keywords: Employee satisfaction, Public services, Service marketing

\footnotetext{
${ }^{1}$ Assist. Prof. Dr., Beykent Univsersity, ISTANBUL/TURKEY, gumus.sefer@gmail.com

${ }^{2} \mathrm{PhD}$ Candidate, Beykent Univsersity, İSTANBUL/TURKEY, gokhanoner@windowslive.com
} 
Gümüş, S., Öner G. (2015). Kamu hizmetlerinin pazarlanması çalışanların mutluluğu ile ölçülür. International

Journal of Social Sciences and Education Research, 1 (2), 380-389.

\section{Giriş}

Çalışan memnuniyeti bireyin işi ile ilgili yaptığı değerlendirme sonucunda oluşan duygusal değişkendir. Çalışan memnuniyetini işin kendisi ile ilgili, parasal, yönetim ve örgütsel faktörler etkilemektedir. Özel hizmet sunan kuruluşlarda olduğu gibi kamu hizmeti sunan kurumlarda da çalışan memnuniyeti hizmet kalitesini önemli oranda etkilemektedir. Kamu çalışanlarının memnuniyeti üzerine yapılan araştırma olduğunu söylemek, yaptıkları hizmetlerden ve yürüttüğü görevlerden yeterince memnun olduklarını anlatmak mümkün değildir. Araştırmanın sonucunda çalışanların çalışma saatleri ve kurumsal hizmetlerden ve iş sağlı̆̆ ve güvenliğinden memnuniyetlerinde sorun yaşadıkları, performans değerlendirmesinden, çalışma mekanı ve güvenlikten, yönetim ve yönetmelikler ve kurumsal aidiyete konularında ise memnun oldukları tespit edilmiştir.

\section{Literatür taraması}

\subsection{Kamu hizmeti}

Kamu hizmeti kavramı farklı disiplinlerin inceleme alanındadır ve pek çok tanımlaması mevcuttur. Bu kavram ilk başlarda siyaset biliminden idare hukukuna geçmiştir. Daha sonraları ise kamu maliyesi ve kamu ekonomisinde değişik şekillerde kullanılmıştır. Günümüzde ise kamu hizmeti siyaset biliminde devletin işlevleri/görevleri şeklinde kullanılırken, kamu ekonomisi ve kamu maliyesi alanında ise "kamu kesimi" ve "kamu malı" anlamında kullanılmaktadır (Karahanoğulları, 2002, s.9).

Kamu hizmeti teorisi ve sistematiği ilk olarak 19. Yüzyıl (yy) sonlarında ve 20. yy başlarında Duguit ve Bordeaux Okulu tarafindan oluşturulmuştur. Günümüze değin pek çok değişim ve gelişmeler göstermiştir. Özellikle 2. Dünya Savası sonrasında devlet müdahalesinin gittikçe artması, iktisadi doktrinlerin tesiri bu değişimlerin başlıca kaynağıdır. Kamu hizmetinde yaşanan bu değişim, tüm ülkelerde etkisini göstermiş ve göstermeye de devam etmektedir. Bu nedenle ortak bir kamu hizmeti tanımı yapılamamaktadır (Ulusoy, 1999, s.165).

Kamu hizmeti öğretide organik, maddi ve şekli bakımdan tanımlanmaktadır. Organik açıdan kamu hizmeti, belli bir örgütü ifade etmektedir. Maddi açıdan kamu hizmeti ise, faaliyetin mahiyetine göre giderilmesinde kamu ihtiyacını karşılayan ve kamusal yararı olan faaliyet olarak tanımlanmaktadır. Şekli açıdan kamu hizmeti de bir faaliyet olarak kullandığı usullere göre belli bir hukuki rejim olarak belirtilmektedir (Giritli, 2013, s.138).

Ülkemizde, kamu hizmeti kavramı geniş kapsamda ele alınmaktadır. Kamu hukuku usulleri uygulanıp uygulanmamasına bakılmaksızın kamu yararı gözetilen birçok hizmet alanı kamu hizmeti olarak düşünülmüştür. Kamu hizmeti, hükümet edenlerin idareleri veya denetimleri altında görülür (Gözler, 2008, s.202). Kamu hizmet kavramının hemen hemen her dönemde devlete ait normlarda düzenleme konusu olmasından idare hukuku açısından önemli olduğu anlaşılmaktadır. (Yılmaz, 2008, s.1216). Yapılan bir tanımlamada kamu hizmeti; devlet veya diğer kamu tüzel kişileri tarafından veya bunların kontrol ve denetimleri altında, toplumun genel ve ortak ihtiyaçlarını karşılamak, kamu yararını sağlamak için ifa edilen devamlı nitelikte faaliyetler olarak nitelendirilmektedir (Onar, 1969, s.13).

\subsection{Kaтu hizmetlerinin sinuflandırılması}

Kamu hizmeti kavramının, hem idare hukukunun uygulama alanının belirlenmesinde belirleyici niteliğe sahip olması, hem de hukuksal rejiminin değişmesi sebebiyle içeriği değişmiş ve 
Gümüş, S., Öner G. (2015). Marketing of public service evaluates with happiness of employees. International Journal of Social Sciences and Education Research, 1 (2), 380-389.

çeşitlenmiştir. Kamu hizmetleri konularına göre İdari Kamu Hizmetleri, İktisadi Kamu Hizmetleri, Sosyal Kamu Hizmetleri ve Bilimsel, Teknik ve Kültürel Kamu Hizmetleri olmak üzere dört sınıfa ayrılmaktadır (Gözübüyük ve Tan, 2004, s.548).

İdari kamu hizmetleri devletin sunduğu bayındırlık, nüfus, tapu-kadastro, sağlık ve eğitim hizmetleri gibi geleneksel kamu hizmetleridir. Bu tür hizmetlerin yürütülmesinde kamu hukuku kuralları ve kamusal yönetim usulleri uygulanır (Günday, 2013, s.304). İdari kamu hizmetlerinin yetkileri, usulleri, personeli, mal ve paraları gibi tüm öğeleri kamu hukuku rejimine tabidir ve bu hizmetlerin eylemlerinden doğan uyuşmazlıklar idari yargının görev kapsamındadır (Duran, 1982, s.317-318). Bir hizmetin iktisadi kamu hizmeti olarak nitelendirilebilmesi için, konusunun ürün/hizmet üretim veya satışını ve yararlanıcılara has hukuk kişilerinin sunduğu hizmetlere benzer bir hizmetin sunulmasını kapsaması gerekmektedir (Tan, 2010, s.193).

Birinci Dünya Savaşı sonrasında devletin üstlendiği hizmetlerle birlikte, klasik kamu hizmetlerinden farklı olarak yeni hizmet türleri ortaya çıkmıştır. Ortaya çıkan bu yeni hizmetler ekonomik alanda yürütülen iktisadi kamu hizmetleri olarak tanımlanmıştır. İktisadi kamu hizmetleri, devletin sanayi, ticaret, maliye ve tarım gibi konularda, özel kişilerle birlikte yaptıkları faaliyetleri kapsamaktadır. İktisadi kamu hizmetleri özel hukuka ve özel hukuk ve kamu hukuku karışımı karma bir hukuk rejimine tabidir (Gözübüyük ve Tan, 2004, s.548).

Sosyal kamu hizmetleri, devlet ve diğer kamu tüzel kişileri tarafından geçmişten beri yürütülen emeklilik, muhtaç kişilere yardım gibi faaliyetler ile özellikle İkinci Dünya Savaşı sonrasında gelişmeye başlayan çalışma düzeni ve sosyal güvenlikle ilgili düzenlemeleri kapsamaktadır. Sosyal kamu hizmetleri faaliyetleri İkinci Dünya Savaşı sonrasında, sosyal devlet anlayışının gelişmesi ile ağırlık kazanmıştır. Sosyal Devlet, insanların birlikte mutlu bir düzene kavuşma eğiliminin bir ürünü olarak gelişmiştir. Sosyalleşme işlemleri ile devlet, kamu hizmetlerinden toplumun daha çok yaralanmalarını sağlayarak hiçbir ayrım gözetmeksizin tüm sosyal sınıfların gereksinmelerini gidermektedir (Çeçen, 1984, s.11).

Bilimsel, teknik ve kültürel kamu hizmetleri müzik, resim, tiyatro gibi kültür alanlarına zamanla devletin de katılmasıyla oluşmuş hizmetlerdir. Bu tür kamu hizmetleri, nitelikleri gereği işletme biçimleri, görev ve yetki kuralları, usul ve isleyişleri ile idari kamu hizmetlerinden farklıdırlar. Bu hizmetlerin yürütülmesinde özerk kuruluşlar, bağımsız personel ve daha serbest bir yapılanma mevcuttur. Kamu ve özel yönetim biçimleri arasında karma bir yapılanma ile bu hizmetler sağlanmaktadır.

\subsection{Kamu hizmetlerinin pazarlanması}

Mal; fiziksel, kimyasal, estetik, sembolik, sanal, sosyo-psikolojik vb. özellikler taşıyan bir pazarlama bileşenidir. Bu bileşendeki sosyo-psikolojik özellikler, tüketici veya müşterinin ona atfettiği bir değer olabilir. Yani malın fiziksel-kimyasal kalitesi yanında, sosyo-psikolojik bir kalitesi de vardır. Üstelik mal yalnızca fiziksel-kimyasal özelliği ile değil ona bazı hizmetler katılarak da pazarlanabilmektedir. Bu hizmetler mala ek bir değer katmakta veya böylesi bir hizmet olmadığı zaman malın fiziksel-kimyasal kalitesi de değer kaybına uğrayabilmektedir. Öte yandan hizmet mala bir değer katarken hizmetin kendisi de çoğu kez saf bir biçimde sunulmamaktadır. Hizmet de belirli seviyelerde bir mal veya mal sistemiyle desteklenebilmektedir. Yani mal ve hizmet bileşeni kısmen birbiri içine girmiştir (Karabulut, 2004, s.121). 
Gümüş, S., Öner G. (2015). Kamu hizmetlerinin pazarlanması çalışanların mutluluğu ile ölçülür. International Journal of Social Sciences and Education Research, 1 (2), 380-389.

Fiziksel ortam çalışanların tatmini, verimliliği ve motivasyonu üzerinde etkilidir. İşletme çalışanları ve tüketicilerin davranışlarını etkileyecek düzeydeki öneminden ötürü hizmet işletmesinin fiziksel ortamının tarafların ihtiyaçlarına aynı anda cevap verecek şekilde düzenlenmelidir. Bu sayede, hem işletme içi örgütsel amaçlara hem de işletme dışı pazarlama amaçlarına ulaşmak mümkün olabilecektir (Üner, 1994, s.6-7). Hizmet pazarlaması ise eylemler, faydalar ve tatmin duygusu yaratan; dokunulmayan, hissedilemeyen, stoklanamayan, sahiplenemeyen, eşzamanlı olarak üretilen ve tüketilen ve adına hizmet denilen şeylerin tüketicilere ulaştırılması ile ilgili faaliyetler bütününe verilen isimdir.

Hizmetlerin soyut olma, resmedilme ve sergileme olanağının bulunmayışı gibi özellikleri tutundurmanın etkin bir biçimde yapılmasını engeller. Ancak, hizmetlerden memnun kalmış tüketiciler çok etkili bir tutundurma aracı olurlar ve hizmetlerin sergilenememe güçlüğünü giderirler. Hizmeti kullanmış ve tatmin olmuş tüketicinin tecrübesini tavsiye etmesi özellikle doktorluk, avukatlık, danışmanlık gibi hizmetlerin pazarlanmasında oldukça önemlidir (Mucuk, 2004, 331).

Gerek ürün gerekse hizmet işletmelerinin hedef pazarını seçmesi ve bu pazarda etkin bir şekilde faaliyet gösterebilmesi pazarlama karması elemanlarının en doğru biçimde değerlendirilip kullanılmasına bağlıdır. Kimi zaman pazarlama karması elemanlarından birinin üzerinde yoğun etkili bir şekilde durulmakta, diğerleri ihmal edilmektedir. Bu durum diğer pazarlama karması elemanlarıyla ilgili yürütülen faaliyetlerin eksikliğini bertaraf edebilmektedir. Bu üstünlük, pazarlama karması elemanlarından malda ya da hizmette, dağıtımda, tutundurma ya da fiyatta üstünlük olabilmektedir. Burada önemli olan faktör hedef pazara uygun pazarlama stratejisinin seçilmesidir (Karahan, 2000, s.14).

\section{Araştırmanın yöntemi}

$\mathrm{Bu}$ araştırmada kamu kurumlarında hizmet sunan çalışanların çalıştıkları kurumlardaki memnuniyet düzeylerini ortaya çıkarmak amacıyla bir anket formu oluşturulmuş ve kamu çalışanlarına uygulanmıştır. Bu bölümde bu anket çalışması ile yapılan araştırmanın gereç ve yöntemine yer verilmiştir. Araştırmanın gereç ve yöntemi ayrı başlıklar halinde ele alınmıştır. Bu başlıklar sırasıyla araştırmanın bölgesi, araştırmanın evreni ve örneklemi, verilerin toplanması ve verilerin analizidir.

\subsection{Araştırmanın evreni ve örneklemi}

Araştırmanın evrenini, kamu kurumlarında hizmet sunan çalışanlar ağırlıklı olmak üzere İstanbul genelindeki kamu kurum ve kuruluşlarında hizmet sunan çalışanlar oluşturmaktadır. Araştırmanın örneklemini ise, sürenin sınırlı olması ve belirli bir bölgede çalışma yapılması nedeniyle, İstanbul'da bir ilçede bulunan ve araştırmaya katılmayı kabul eden kamu çalışanları oluşturmaktadır.

\subsection{Verilerin toplanmast}

$\mathrm{Bu}$ araştırmada veri toplama yöntemi olarak anket kullanılmıştır. Kamu kurumlarında çalışanlara hazırlanan memnuniyet anketi uygulanmıştır. Uygulamadan önce araştırmanın amacı ile ilgili kısa bir yazılı açıklamada bulunulmuştur. Anket formunda toplam 33 soru yer almaktadır. Ankette çalışan memnuniyeti boyutlarının sorgulandığı çalışma saatleri ve kurumsal hizmetlere ilişkin 4 soru, performans değerlendirmesine ilişkin 2 soru, iş sağlığ 1 ve güvenliğine ilişkin 5 soru, meslek, çalışma mekanı ve güvenliğe ilişkin 6 soru, yönetim ve yönetmeliklere ilişkin 5 soru, kurumsal 
Gümüş, S., Öner G. (2015). Marketing of public service evaluates with happiness of employees. International Journal of Social Sciences and Education Research, 1 (2), 380-389.

bağlılığa ilişkin 2 soru yer almaktadır. Bu konuların dışında diğer hususlar başlığı altında katılımcıların demografik faktörlerinin sorgulandığ 8 soru bulunmaktadır.

\subsection{Verilerin analizi}

İstanbul genelinde ve bir İlçe'de bulunan kamu kurum ve kuruluşlarında hizmet sunan çalışanlar ağırlıklı olmak üzere İstanbul genelindeki kamu kurumlarında hizmet sunan 117 çalışana uygulanan anket ile sorular sorulmuş ve toplanan veriler SPSS for Windows v. 17.0 programı ile çözümlenmiştir. Veriler çözümlenmeden önce EDA (Exploratory Data Analysis/Açıklayııı Veri Analizi) ile toplanan verilerin belirlenen sınırlar içinde olup olmadığı kontrol edilmiş ve gerekli düzeltmeler yapılmıştır.

\section{Bulgular ve yorumlar}

\section{1. Çalışma saatleri ve kurumsal hizmetlere iliş̧kin bulgular}

Örneklem grubunu oluşturan çalışanların haftalık mesai süresinden fazla çalışılması durumuna göre dağılımı Tablo 1'de verilmiştir. Haftalık mesai süresinden fazla çalışılması durumu dağıllmına bakıldığında örneklemin \%76,1'inin fazla çalışmadı̆̆ $1, \% 23,9$ 'unun ise haftalık mesai süresinden fazla çalıştı̆̆ görülmektedir.

Tablo 1. Haftalık mesai süresinden fazla çalışılması durumu

\begin{tabular}{|l|r|r|r|r|}
\hline Fazla Mesai & \multicolumn{1}{|c|}{$\boldsymbol{f}$} & \multicolumn{1}{c|}{ \% } & \multicolumn{1}{c|}{ Geçerli \% } & \multicolumn{1}{c|}{ Yığılmalı \% } \\
\hline Evet & 28 & 23,9 & 23,9 & 23,9 \\
\hline Hayır & 89 & 76,1 & 76,1 & 100,0 \\
\hline Toplam & 117 & 100,0 & 100,0 & \\
\hline
\end{tabular}

Kurumda çocuklu çalışanlar için yuva veya kreş bulunması durumu incelendiğinde $\% 89,7$ oranında kurumda yuva veya kreş bulunmadığ $1, \% 2,6$ oranında kurumda yuva veya kreş bulunduğu tespit edilmiştir (Tablo 2).

Tablo 2. Kurumda çocuklu çalışanlar için yuva veya kreş bulunması durumu

\begin{tabular}{|l|r|r|r|r|}
\hline Yuva veya Kreş & \multicolumn{1}{|c|}{$\boldsymbol{f}$} & \multicolumn{1}{c|}{ \% } & Geçerli \% & \multicolumn{1}{c|}{ Yığılmalı \% } \\
\hline Evet & 3 & 2,6 & 2,6 & 2,6 \\
\hline Hayır & 105 & 89,7 & 89,7 & 92,3 \\
\hline İhtiyaç yok & 9 & 7,7 & 7,7 & 100,0 \\
\hline Toplam & 117 & 100,0 & 100,0 & \\
\hline
\end{tabular}

\subsection{Değerlendirme (performans değerlendirmesi)'ne ilişkin bulgular}

Araştırmaya katılan çalışanların kurumda idare tarafından ödüllendirilmesi durumu dağılımı Tablo 3 'te verilmiştir. Bu dağılıma göre \%53,8 oranında çalışan kısmen ödüllendirilmekte, \%29,9 oranında çalışan ödüllendirilmemekte ve $\% 16,2$ oranında çalışan ise ödüllendirilmemektedir. 
Gümüş, S., Öner G. (2015). Kamu hizmetlerinin pazarlanması çalışanların mutluluğu ile ölçülür. International Journal of Social Sciences and Education Research, 1 (2), 380-389.

Tablo 3. Kurumda idare tarafından çalışanların ödüllendirilmesi durumu

\begin{tabular}{|l|r|r|r|r|}
\hline Ödüllendirilme & \multicolumn{1}{c|}{$\boldsymbol{f}$} & \multicolumn{1}{c|}{ \% } & \multicolumn{1}{c|}{ Geçerli \% } & \multicolumn{1}{c|}{ Yığılmalı \% } \\
\hline Evet tamamen & 19 & 16,2 & 16,2 & 16,2 \\
\hline Evet kısmen & 63 & 53,8 & 53,8 & 70,1 \\
\hline Hayır & 35 & 29,9 & 29,9 & 100,0 \\
\hline Toplam & 117 & 100,0 & 100,0 & \\
\hline
\end{tabular}

\section{3. $\dot{I}_{S ̧}$ sağll $\breve{g} l$ ve güvenliğine ilişkin bulgular}

Son 1 yılda çalışanlara güvenlik ve haklar konusunda eğitim düzenlenmesi durumuna bakıldığında $\% 72,6$ oranında düzenlenmediği, \%14,5 oranında düzenlendiği tespit edilmiştir (Tablo 4).

Tablo 4. Son 1 yılda güvenlik ve haklar konusunda eğitim düzenlenmesi durumu

\begin{tabular}{|l|r|r|r|r|}
\hline Ĕgitim & \multicolumn{1}{|c|}{$\boldsymbol{f}$} & \multicolumn{1}{c|}{$\%$} & \multicolumn{1}{c|}{ Geçerli \% } & \multicolumn{1}{c|}{ Yı̆̆ılmalı \% } \\
\hline Evet & 17 & 14,5 & 14,5 & 14,5 \\
\hline Kismen & 15 & 12,8 & 12,8 & 27,4 \\
\hline Hayır & 85 & 72,6 & 72,6 & 100,0 \\
\hline Toplam & 117 & 100,0 & 100,0 & \\
\hline
\end{tabular}

Kurumda kazaları önlemeye yönelik teknik altyapı bulunması durumu incelendiğinde Tablo 5 'den de görüldüğü üzere $\% 49,6$ oranında altyapının bulunmadığı, $\% 16,2$ oranında bulunduğu tespit edilmiştir (Tablo 5).

Tablo 5. Kurumda kazaları önlemeye yönelik teknik altyapı bulunması durumu

\begin{tabular}{|l|r|r|r|r|}
\hline Altyapı & \multicolumn{1}{|c|}{$\boldsymbol{f}$} & \multicolumn{1}{c|}{$\%$} & \multicolumn{1}{c|}{ Geçerli \% } & \multicolumn{1}{c|}{ Yı̆̆ılmalı \% } \\
\hline Evet var & 19 & 16,2 & 16,2 & 16,2 \\
\hline Evet, kısmen var & 40 & 34,2 & 34,2 & 50,4 \\
\hline Hayır, yok & 58 & 49,6 & 49,6 & 100,0 \\
\hline Toplam & 117 & 100,0 & 100,0 & \\
\hline
\end{tabular}

\subsection{Meslek, çalışma mekanı ve güvenliğe ilişkin bulgular}

Kurumda yazılı bir görev tanımı bulunması durumu incelendiğinde \%70,9 oranında bulunduğu, $\% 21,4$ oranında ise bulunmadığ 1 tespit edilmiştir. \%7,7 oranında çalışan ise görev tanımı bulunup bulunmadığını bilmemektedir (Tablo 6).

Tablo 6. Kurumda yazılı bir görev tanımı bulunması durumu

\begin{tabular}{|l|r|r|r|r|}
\hline Görev Tanımı & \multicolumn{1}{|c|}{$\boldsymbol{f}$} & \multicolumn{1}{c|}{$\boldsymbol{\text { \% }}$} & \multicolumn{1}{c|}{ Geçerli \% } & \multicolumn{1}{c|}{ Yı̆̆ılmalı \% } \\
\hline Evet & 83 & 70,9 & 70,9 & 70,9 \\
\hline Hayır & 25 & 21,4 & 21,4 & 92,3 \\
\hline Bilmiyorum & 9 & 7,7 & 7,7 & 100,0 \\
\hline Toplam & 117 & 100,0 & 100,0 & \\
\hline
\end{tabular}


Gümüş, S., Öner G. (2015). Marketing of public service evaluates with happiness of employees. International Journal of Social Sciences and Education Research, 1 (2), 380-389.

Çalışma mekanının ergonomik düzenlenmesi durumu sorgulandığında, $\% 41,9$ oranında düzenlenmediği, \%29,9 oranında düzenlendiği görülmektedir. \%28,2 oranında çalışan ise bu konuda bilgi sahibi değildir (Tablo 7).

Tablo 7. Çalışma mekanının ergonomik düzenlenmesi durumu

\begin{tabular}{|l|r|r|r|r|}
\hline Ergonomik & \multicolumn{1}{|c|}{$\boldsymbol{f}$} & \multicolumn{1}{c|}{$\boldsymbol{\%}$} & \multicolumn{1}{c|}{ Geçerli \% } & \multicolumn{1}{c|}{ Yı̆̆ılmalı \% } \\
\hline Evet yeterince & 35 & 29,9 & 29,9 & 29,9 \\
\hline Kısmen düzenlenmiş & 49 & 41,9 & 41,9 & 71,8 \\
\hline Hayır, düzenleme yok & 33 & 28,2 & 28,2 & 100,0 \\
\hline Toplam & 117 & 100,0 & 100,0 & \\
\hline
\end{tabular}

\subsection{Yönetim ve yönetmeliklere ilişkin bulgular}

Yöneticilere çalışanların sorunlarını iletilmesi durumu incelendiğinde $\% 46,2$ oranında çalışanın her zaman iletebildiği, \%40,2 oranında çalışanın bazen iletebildiği, \%13,7 oranında çalışanın iletemediği tespit edilmiştir (Tablo 8).

Tablo 8. Yöneticilere sorunların iletilebilmesi durumu

\begin{tabular}{|l|r|r|r|r|}
\hline Sorunları İletme & \multicolumn{1}{|c|}{$\boldsymbol{f}$} & \multicolumn{1}{c|}{$\boldsymbol{\%}$} & \multicolumn{1}{c|}{ Geçerli \% } & \multicolumn{1}{c|}{ Yı̆̆IImalı \% } \\
\hline Evet, her zaman & 54 & 46,2 & 46,2 & 46,2 \\
\hline Evet, bazen & 47 & 40,2 & 40,2 & 86,3 \\
\hline Hayır & 16 & 13,7 & 13,7 & 100,0 \\
\hline Toplam & 117 & 100,0 & 100,0 & \\
\hline
\end{tabular}

\subsection{Kurumsal aidiyete ilişkin bulgular}

Çalışanların çalıştıkları kurumdan ayrılmayı düşünmeleri durumu incelendiğinde $\% 51,3$ oranında bazen düşündükleri, $\% 16,2$ oranında sık sık düşündükleri, $\% 32,5$ oranında ise çalışanların kurumdan ayrılmayı düşünmedikleri görülmektedir (Tablo 9).

Tablo 9. Çalışılan kurumdan ayrılmanın düşünülmesi durumu

\begin{tabular}{|l|r|r|r|r|}
\hline Kurumdan Ayrılma & \multicolumn{1}{|c|}{$\boldsymbol{f}$} & \multicolumn{1}{c|}{$\%$} & \multicolumn{1}{c|}{ Geçerli \% } & \multicolumn{1}{c|}{ Yı̆̆ılmalı \% } \\
\hline Evet, sık sık & 19 & 16,2 & 16,2 & 16,2 \\
\hline Evet, bazen & 60 & 51,3 & 51,3 & 67,5 \\
\hline Hayır & 38 & 32,5 & 32,5 & 100,0 \\
\hline Toplam & 117 & 100,0 & 100,0 & \\
\hline
\end{tabular}

\section{Sonuç ve öneriler}

Türkiye'nin özelleştirmeye geçiş sürecinden bu yana devlet bir çok hizmetini özel sektöre devretmiştir. Bundan böyle devlet hizmetlerinin görülebilmesi ve halkına hizmet verebilmesi için devletin de pazarlamaya ihtiyaç vardır. Devletin de kar etmeye ihtiyacı vardır. Bu nedenle faydamaliyet analizlerinin yapılması, mal ve hizmetlerinin tanıtılması, satış ve pazarlama ile reklam değişkenlerinin kullanılması kamu hizmetlerinin yararına olacaktır. Araştırmada elde edilen bulgulardan demografik faktörlere göre \%59 oranında kadın, \%41 oranında erkek çalışanın araştırmaya katılmış olduğu sonucuna ulaşılmıştır. $17-20$ yaş ile 50 yaş üstü yaş aralığında çalışanın 
Gümüş, S., Öner G. (2015). Kamu hizmetlerinin pazarlanması çalışanların mutluluğu ile ölçülür. International Journal of Social Sciences and Education Research, 1 (2), 380-389.

katıldığ 1 araştırmanın örnekleminde en büyük katılımcı oranının \%25,6 ile 31-35 yaş grubunda olduğu ve unvan olarak araştırmaya büyük oranda \%42,7 oranı ile VHKİ' lerin katılmış olduğu elde edilen bir diğer sonuçtur. Öğretmen, Şef, Doktor, Müdür, Hizmetli, Mühendis ve bunların dışında olan bazı çalışanlar da araştırmaya katılmıştır.

Araştırmaya katılan çalışanların kurumda toplam çalışma süresine göre en büyük oranın $\% 22,2$ ile 15 yıldan fazla çalışmakta olanlarda olduğu tespit edilmiştir. Çalışılan kurumların \%47'sinde, neredeyse yarısında öğle yemeği verilmemekte olduğu ve aynı şekilde kurumların yarısında (\%49,6 oranında) işe geliş gidişlerde servis hizmeti uygulanmamakta olduğu araştırmanın sonunda tespit edilmiştir. Çalışılan kurumda öğle yemeği verilmemesi ve servis olmaması çalışan memnuniyetini etkilemektedir. Araştırmaya katılan çalışanların yasal izin hakkını kullanabildikleri de elde edilen bulgular arasındadır. Çalışan memnuniyetinin arttırılması için kurumlarda öğle yemeği hizmeti olmalı ve işe gidiş gelişlerde servis hizmetinin bulunması gerektiği düşünülmektedir.

Çalışma saatleri ve kurumsal hizmetlerden duyulan memnuniyetin arttırılması için İK' nın daha etkin kullanılması ve çocuklu çalışanlar için kreş imkanının sağlanması gerekmektedir. Çalışan memnuniyetinin yükseltilebilmesi için önemli kriterlerden biri ödüllendirilmedir ve çalışanların daha fazla ödüllendirilmesi gerekmektedir. Çalışan memnuniyetinin artırılması için çalışanlara güvenlik konusunda eğitimler yapılmalı, kazaları önlemeye yönelik teknik altyapı oluşturulmalı, bununla birlikte güvenliğin sağlanması için düzenleyici ve önleyici faaliyetlerde bulunulmalıdır. Yazılı görev tanımı olması, çalışma ortamının ergonomik düzenlenmesi, çalışanlara mobing uygulanmaması, çalışanların memnuniyetlerini arttırmaktadır. Memnuniyet oranının arttırılabilmesi için kimi konularda çalışanların da görüşlerine başvurulması ve onların önerilerinin dikkate alınması gerekmektedir.

\section{Kaynakça}

Çeçen, A., (1984). Sosyal Demokrasi, Devinim Yayınları, Ankara, s.11.

Duran, L., (1982). İdare Hukuku Ders Notları, İstanbul Üniversitesi Yayınları, İstanbul, s.317-318.

Giritli, İ. (2013). İdare Hukuku, 6. Bask1, Der Yayınları, İstanbul, s. 138.

Gözler, K. (2008). İdare Hukukuna Giriş, Ekin Yayınevi, Bursa, s. 202.

Gözübüyük, A. Ş. ve Tan, T., (2004). İdare Hukuku Cilt 1,Turhan Kitabevi, Ankara, s.548.

Günday, M., (2013). İdare Hukuku, 10. Bask1, İmaj Yayınevi, Ankara, s.304.

Karabulut, M., (2004). Ulusal ve Küresel Pazarlarda Stratejik Pazarlama Yönetimi, Üniversal Bilimsel Yayınları, İstanbul, s.121.

Karahan, K., (2000). Hizmet Pazarlaması, Beta Basım Yayım Dağıtım A.Ş., İstanbul, s.14.

Karahanoğulları, O., (2002). Kamu Hizmeti (Kavram ve Hukuksal Rejim), Turhan Kitabevi, Ankara, s. 9.

Mucuk, İ., (2004). Pazarlama İlkeleri, Türkmen Kitabevi, İstanbul, s.331.

Onar, S., (1969). İdare Hukukunun Umumi Esasları, İsmail Akgün Matbaacılık, İstanbul, s. 13.

Tan, T., (2010). Ekonomik Kamu Hukuku Dersleri, Seçkin Yayıncılık, Ankara, s. 193.

Ulusoy, A. (1999). Fransız ve Avrupa Birliği Kamu Hizmeti Anlayışlarının Türk Hukukuna Etkisi, Ankara Üniversitesi Hukuk Fakültesi Dergisi (AÜHFD), Cilt: 48, Sayı: 1-4, Ankara, s. 165.

Üner, M., (1994). Hizmet Pazarlamasında Pazarlama Karması Elemanları Değişiklik Gösterir mi?, Pazarlama Dünyası Dergisi, Y11: 8, Sayı: 43, s. 6-7.

Yılmaz, D., (2008). Türk Hukukunda Kamu Hizmeti Kavramı ve Kriterleri, Gazi Üniversitesi Hukuk Fakültesi Dergisi, Cilt: 12, Sayı: 1-2, Ankara, s. 1216. 
Gümüş, S., Öner G. (2015). Marketing of public service evaluates with happiness of employees. International Journal of Social Sciences and Education Research, 1 (2), 380-389.

\section{Extended abstract in English}

Purpose and Significance: Employee satisfaction is an emotional variables. It occurs about the business results of the individual. Financial, management and organizational factors influences to the employee satisfaction. Employee satisfaction detects the quality of service in the public services. We can not say that they are happy enough. We can say that they are happy from the safety, management and regulations. State is a concept. Government manages the states. Civil servant works all levels of the state. Duties and responsibilities are determined by the laws and regulations. Happiness and satisfaction of the employees ensure successful implementation of government services. It is very important for the future of the state. Employee satisfaction tell us loyalty of the state. Satisfaction of employees in state institutions and the people in general and not about loyalty to the authorities, the state pass through the love and respect of the legal entity. State continuity is essential. Not depends on the person, should be determined devotion to duty. If the satisfaction level measures, public confidence in the state will strengthen. Public services influences happiness and satisfaction of the employees. The States turned over the main task to the private sector. Public service needs to marketing. Our research is also included in this variable.

Literature: The public service is in the study area and there are many definitions of the different disciplines. This concept has passed from politics to the administration law. Later, it has been used in different ways in the public finance and public economics. Today we can see it public and public domain (Karahanoğulları, 2002). These shifts in public service, have an impact in all countries and continues (Ulusoy, 1999). In our country, it is discussed in the broad scope of the concept of public service. Many service areas of public benefits is intended as a public service (Gözler, 2008).

We can say that public services has four groups. Administrative public services, economic public services, social public services and scientific, technical and cultural public services (Gözübüyük ve Tan, 2004). Administrative public services provide about population, cadastro, education and traditional services. They implements public law and public administration procedures (Günday, 2013). Scientific, technical and cultural public services was formed by the state with music, painting and theater. They are different from administrative public services. They have independent staff and a more liberal structure. There is a composite structure between public and private management.

Performance management is an approach of a systematic management, which provides more efficient results from the employee potentials. Therefore, the data obtained from the performance management system, which forms a part of the human resources management system are being used as a strategic tool with the intention of the achievement of competition superiority and continuous development of the organisations. An employee of every level will take place in the organisation in order to fulfil a certain activity and the employee is executing this activity for the organisation with the help of his/her mental abilities, knowledge and personality. The most common performance scale is the time, quality, costing and material, health and security standards. The organisations prepare and implement their performance management systems in accordance with their requirements and the specifications of their organisation.

Goods has physical, chemical, aesthetic, symbolic and socio-psychological characteristics. They have physical quality and socio-psychological quality. Services are supported by a certain level of goods or merchandise system. The service marketing have actions, benefits and create a 
Gümüş, S., Öner G. (2015). Kamu hizmetlerinin pazarlanması çalışanların mutluluğu ile ölçülür. International Journal of Social Sciences and Education Research, 1 (2), 380-389.

sense of satisfaction. You can not touch it. You can not feel it. You can not stored it and you can not ownership it. Appropriate marketing strategy must be selected to the target market (Karahan, 2000).

Methodology: The research is made by a survey that is implemented 117 public workers. At the end of research identified that the workers aren't satisfied about working hours and corporate services and occupational health and safety, the workers are satisfied about performance evaluation, profession, working place and safety, management and regulations and institutional commitment.

Results and Conclusion: Turkey's government have been transferred many services to the private sector since the transition to privatize. The state also needs to make profit. According to demographic factors, fifty nine percent female and forty one percent male employees participated in the study. The largest proportion of the total working hours of the employees in the institutions participating in the study was fifteen years and twenty two point two percent were found to be more in the works. Not given lunch at work and lack of corporate service affects employee satisfaction. They can use the legal permits. It must be lunch service and transport service for employee satisfaction. It must be kindergarten and human resources must be more effective. Having written job descriptions, ergonomic arrangement of the workplace, mobbing not apply to employees, increase employee satisfaction. Employees needs to be more rewarded. 